\title{
Seasonal Predictability of Wintertime Precipitation in Europe Using the Snow Advance Index
}

\author{
S. BRANDS, R. MANZANAS, AND J. M. GuTIÉRREZ \\ Instituto de Física de Cantabria (CSIC-UC), Santander, Spain \\ J. COHEN \\ Atmospheric and Environmental Research, Lexington, Massachusetts
}

(Manuscript received 31 January 2012, in final form 22 March 2012)

\begin{abstract}
This study tests the applicability of Eurasian snow cover increase in October, as described by the recently published snow advance index (SAI), for forecasting December-February precipitation totals in Europe. On the basis of a classical correlation analysis, global significance was obtained and locally significant correlation coefficients of up to 0.89 and -0.78 were found for the Iberian Peninsula and southern Norway, respectively. For a more robust assessment of these results, a linear regression approach is followed to hindcast the precipitation sums in a 1-yr-out cross-validation framework, using the SAI as the only predictor variable. With this simple empirical approach, local-scale precipitation could be reproduced with a correlation of up to 0.84 and 0.71 for the Iberian Peninsula and southern Norway, respectively, while catchment aggregations on the Iberian Peninsula could be hindcast with a correlation of up to 0.73 . These findings are confirmed when repeating the hindcast approach to a degraded but much longer version of the SAI. With the recommendation to monitor the robustness of these results as the sample size of the SAI increases, the authors encourage its use for the purpose of seasonal forecasting in southern Norway and the Iberian Peninsula, where general circulation models are known to perform poorly for the variable in question.
\end{abstract}

\section{Introduction}

In a recently published study, Cohen and Jones (2011) demonstrated that the wintertime Arctic Oscillation (AO) as well as the concurrent temperature and mean sea level pressure anomalies over a large fraction of the Northern Hemispheric extratropics are statistically associated with Eurasian snow cover during the previous October. To describe the latter, they introduce the snow advance index (SAI), which, as an alternative to more sophisticated numerical simulations (Palmer et al. 2004), is proposed as a simple measure of seasonal prediction (Goddard et al. 2001). Theoretical considerations on the physical ground of this statistical link were provided by Cohen et al. (2007), who presented a conceptual model for how Eurasian snow cover in the fall can modulate the

Corresponding author address: Swen Brands, Instituto de Física de Cantabria (CSIC-UC), Avenida de los Castros, Santander 39005, Spain.

E-mail: brandssf@unican.es phase and magnitude of the following winter AO. For example, when snow cover is above normal, this leads to a strengthened Siberian high and colder surface temperatures across northern Eurasia. The intensification of the Siberian high, along with the thermal impacts of enhanced snow cover and topographic forcing, corresponds to a positive wave activity flux anomaly in the late fall and early winter, leading to stratospheric warming and to a lagging tropospheric negative $\mathrm{AO}$ response in winter.

As wintertime precipitation anomalies in Europe are well known to be associated with the North Atlantic Oscillation (Hurrell 1995; Rodriguez-Puebla et al. 2001), which can be interpreted as the regional manifestation of the AO (Cohen and Barlow 2005), we expect the SAI to be a simple tool for seasonal prediction in this area. This hypothesis is tested here, by relating it to precipitation totals of the following December-February (DJF) season, using gridded observations and station data. The importance of this effort becomes evident when taking into account that the predictive power of global circulation models is known to be poor for DJF precipitation in 


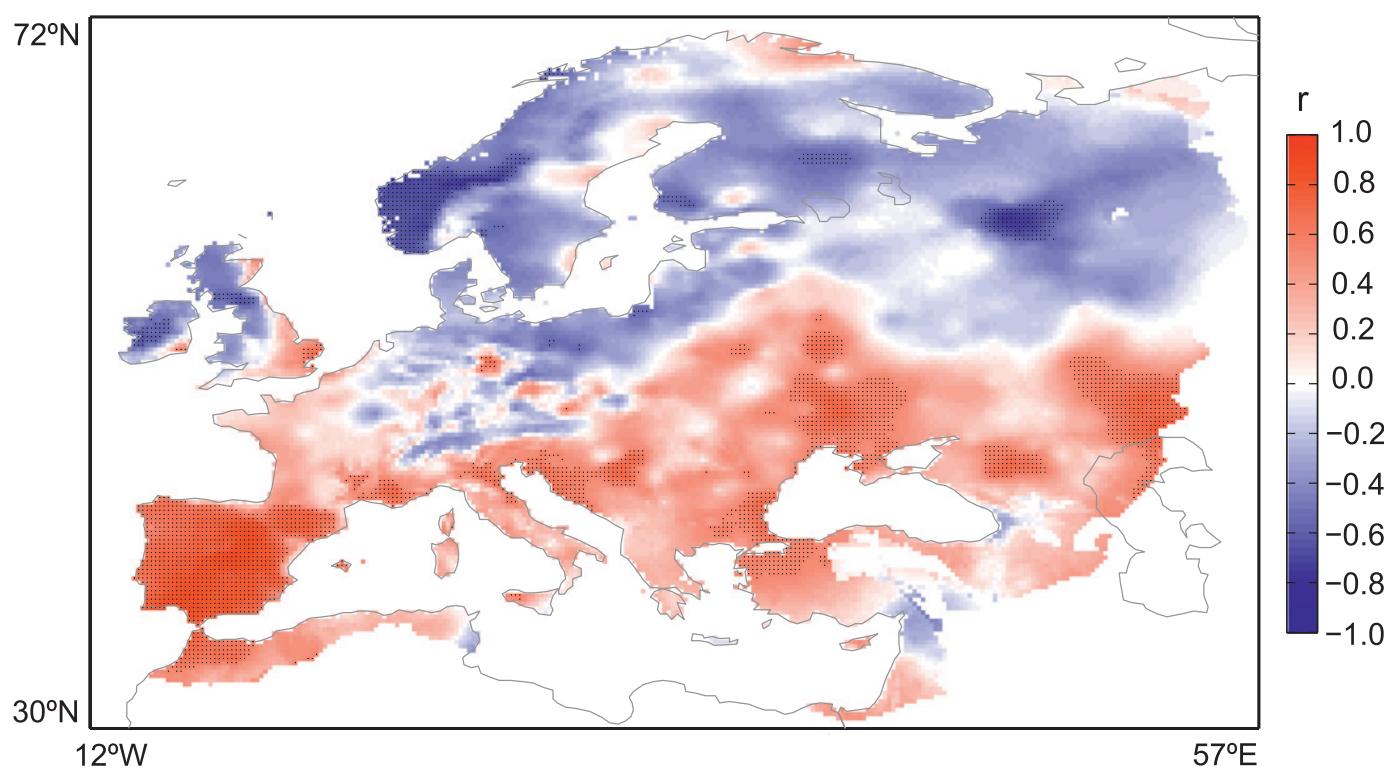

FIG. 1. Pearson correlation coefficients between the October daily SAI and the precipitation sums of the following DJF $(n=14$; critical value $= \pm 0.53)$. Locally significant correlations $\left(\alpha_{\text {local }}=0.05\right)$ are shaded in black. Global significance was obtained $\left(\alpha_{\text {global }}=0.05\right)$; all calculations are based on E-OBS.

Europe (Doblas-Reyes et al. 2009). Consequently, if this variable could be skillfully forecast one month ahead using a single empirical index, this would considerably ease the decision-making process of stakeholders involved in seasonal prediction (García-Morales and Dubus 2007).

\section{Data}

Daily accumulated precipitation data are taken from the recently updated (fifth) version of the EnsemblesBased Predictions of Climate Changes and Their Impacts gridded dataset (E-OBS) (Haylock et al. 2008), which comes on a resolution of $0.25^{\circ}$ and, regarding the density of the underlying station network, has been considerably improved with respect to earlier versions. To test for a possible dataset dependence of the results, we additionally repeat our analysis with station data from the European Climate Assessment and Dataset (ECA\&D) project (Klein Tank et al. 2002; Klok and Klein Tank 2009) as well as a high-quality precipitation series provided by the Spanish Meteorological Agency [Agencia Estatal de Meteorología (AEMET)]. The daily precipitation sums are aggregated to DJF totals for each year. Note that skewness and outliers are present in the data, which has to be taken into account in the subsequent analysis (see section 3).

For the predictor variable, we use both the daily and weekly versions of the SAI (Cohen and Jones 2011). These standardized indices measure the rate of increase of Eurasian snow cover in October, as described by the regression coefficient of the least squares fit of the daily/ weekly Eurasian snow cover extension in a geographical domain covering $25^{\circ}-60^{\circ} \mathrm{N}, 0^{\circ}-180^{\circ} \mathrm{E}$. The daily SAI was calculated upon satellite retrievals from the Interactive Multisensor Snow and Ice Mapping System (IMS), which are available on a resolution of $24 \mathrm{~km}$ for each day from 1997 onward (Ramsay 1998). The weekly SAI, in turn, was obtained from the National Oceanic and Atmospheric Administration (NOAA)'s satellite-sensed observations, offering a much longer time series (from 1972 onward) at the expense of a lower temporal and spatial resolution (Robinson et al. 1993). While the E-OBS and ECA\&D data are available until DJF 2010/11, the last winter is not covered by the Spanish station data, leading to a sample size of $n=14 / 13(n=39 / 38)$ in case of applying the daily (weekly) SAI.

\section{Methods}

To assess the statistical relationship between October SAI and DJF precipitation, the Pearson correlation coefficient $r$ was applied. The $p$ value of a given $r$ was calculated using a two-sided Student's $t$ test (null hypothesis: $r=0$ ). To account for skewness and outliers, all results were double-checked by using the Spearman rank correlation in addition to the Pearson correlation. Both measures led to similar results.

To test for the effect of temporal autocorrelation on the significance of our results, we computed the lag-1 


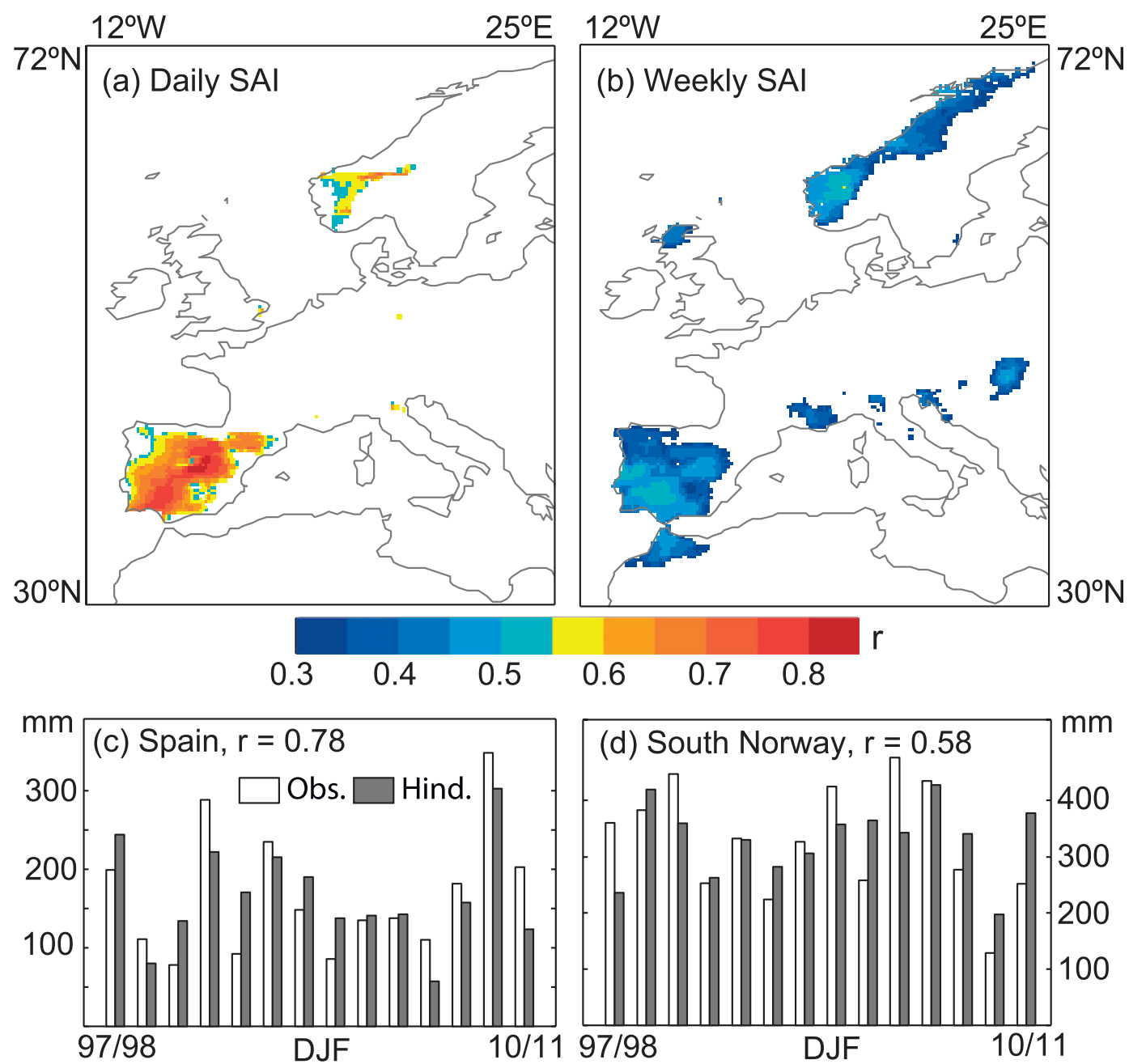

FIG. 2. Significant $\left(\alpha_{\text {local }}=0.05\right) r$ between hindcast and observed DJF precipitation sums, applying (a) the daily SAI $(n=14$; critical value $=0.53)$ and $(b)$ the weekly SAI $(n=39$; critical value $=0.32)$. Spatially averaged hindcasts based on the daily SAI are contrasted against its corresponding observations for (c) Spain and (d) southern Norway; all calculations are based on E-OBS.

autocorrelation coefficients of the applied time series and found them to be significant $(\alpha=0.05)$ in less than $5 \%$ of all cases. Thus, the unwanted effect of committing too many type 1 errors due to serial correlation (Kristjánsson et al. 2002) is negligible in this study. Similarly, a linear detrending of the applied time series did not change the results either.

To assess the global significance of the computed correlations, we used the method described in Livezey and Chen (1983). In this case, the $t$ test was applied to a Gaussian random sample (which substitutes the SAI sample) and the observational time series from E-OBS. Subsequently, the percentage of grid boxes where $p$ values below 0.05 were found - that is, the null hypothesis of zero correlation was erroneously rejected- was calculated. By repeating this procedure a thousand times, a sample of 1000 areal fractions was generated, whose corresponding 95th percentile defines the critical value for declaring global significance at a test level of $5 \%$.

For the purpose of operational seasonal forecasting, a 1-yr-out cross-validation approach (Michaelsen 1987) is applied for each grid box or station: Each of the $i=$ $1,2, \ldots, n$ DJF precipitation sums is hindcasted with the regression equation obtained from regressing the remaining $n-1$ SAI values against its corresponding precipitation sums. By repeating this approach $n$ times, a complete hindcast obtained from out-of-sample predictor data is reconstructed, which is then validated against its corresponding observations by using the 


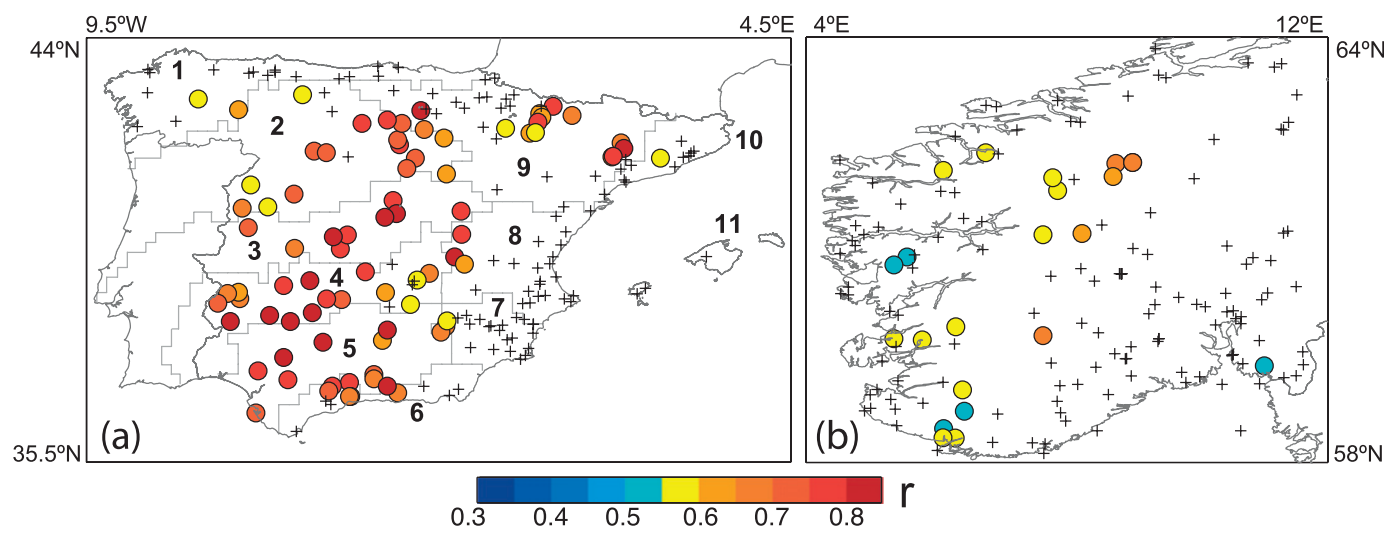

FIG. 3. Significant $\left(\alpha_{\text {local }}=0.05\right) r$ between hindcast and observed DJF precipitation sums based on the daily SAI, using (a) AEMET station data for Spain $(n=13$; critical value $=0.55)$ and (b) ECA\&D station data for southern Norway $(n=14$; critical value $=0.53)$; also shown are the Spanish hydrological catchments as defined in Table 1.

Pearson correlation. The resulting coefficients are referred to as "hindcast correlations."

\section{Results}

Figure 1 maps the Pearson correlation coefficient between the October daily SAI and the precipitation totals of the following DJF season for the E-OBS gridded dataset. Global significance $\left(\alpha_{\text {global }}=0.05\right)$ was obtained, and locally significant $\left(\alpha_{\text {local }}=0.05\right)$ correlations are most evident and spatially consistent on the Iberian Peninsula and southern Norway, yielding values of up to 0.89 and -0.78 , respectively.

Predictability for the above-mentioned two regions is confirmed by the hindcasts obtained from out-ofsample predictor data and using both gridded data from E-OBS (see Fig. 2a) and station data from AEMET and ECA\&D (see Fig. 3). Note that only the areas of significant hindcasts $\left(\alpha_{\text {local }}=0.05\right)$-also referred to as "skillful hindcasts"- are shown. Over the Iberian Peninsula and southern Norway, local DJF precipitation sums can be hindcast with an accuracy of up to 0.84 and 0.71 , respectively.

When using the longer weekly SAI (see Fig. 2b), these findings are generally confirmed. Hindcast correlations are systematically lower than for the daily index, which is expected due to the lower accuracy of the underlying satellite data and the resulting weaker link to the wintertime AO (Cohen and Jones 2011). However, because of the larger sample size, the area of significant skill $\left(\alpha_{\text {local }}=0.05\right)$ extends along the whole western Scandinavian Peninsula. These results are confirmed when repeating the hindcast approach for station data from AEMET and ECA\&D (not shown) and thus have little sensitivity to the choice of dataset. Note that areas of significant skill outside the above-mentioned regions could generally not be confirmed by the station data and hence are not considered in this study.

To assess the performance of the empirical forecasting approach on subcontinental to catchment scale, spatially aggregated hindcasts and observations were compared for southern Norway (south of the Bergen Fjord at $64^{\circ} \mathrm{N}$ ) and the Iberian Peninsula (see Table 1).

When applying the daily SAI $(n=14)$, significant $(\alpha=$ 0.05 ) correlations of 0.58 and 0.61 are found for southern Norway and Portugal, respectively, while the results for

TABLE 1. Pearson correlation between hindcast and observed DJF precipitation totals, aggregated to catchment, country, and subcontinental scale; one or two asterisks are assigned in case correlation is significant at a test level of $5 \%$ or $1 \%$, respectively.

\begin{tabular}{cllc}
\hline \hline Catchment & $\begin{array}{c}\text { Area of } \\
\text { aggregation }\end{array}$ & $\begin{array}{c}\text { Daily SAI } \\
(n=14)\end{array}$ & $\begin{array}{c}\text { Weekly SAI } \\
(n=39)\end{array}$ \\
\hline 1 & Norte & 0.51 & $0.37^{*}$ \\
2 & Duero & $0.64^{*}$ & $0.42^{* *}$ \\
3 & Tajo & $0.71^{* *}$ & $0.51^{* *}$ \\
4 & Guadiana & $0.73^{* *}$ & $0.50^{* *}$ \\
5 & Guadalquivir & $0.67^{* *}$ & $0.49^{* *}$ \\
6 & Sur & 0.49 & $0.44^{* *}$ \\
7 & Segura & 0.34 & 0.16 \\
8 & Levante & $0.63^{*}$ & 0.28 \\
9 & Ebro & $0.68^{* *}$ & 0.31 \\
10 & Catalana & 0.39 & 0.16 \\
11 & Baleares & 0.40 & 0.03 \\
& Portugal & $0.61^{*}$ & $0.49^{* *}$ \\
& Spain & $0.78^{* *}$ & $0.47^{* *}$ \\
& Iberian Peninsula & $0.75^{* *}$ & $0.48^{* *}$ \\
& Southern Norway & $0.58^{*}$ & $0.43^{* *}$ \\
\hline
\end{tabular}


Spain and the Iberian Peninsula as a whole ( 0.78 and 0.75 , respectively) are highly significant $(\alpha=0.01)$. To give a visual example, the time series for southern Norway and Spain are plotted in Figs. 2c,d. With regard to the catchments of Iberian Peninsula (see Table 1; Fig. 3a), hindcast correlations are highly significant for the Guadiana (0.73), Tajo (0.71), Ebro (0.68), and Guadalquivir (0.67) and significant for the Duero (0.64) and Levante (0.63) (see Table 1, third column). These results are confirmed when applying the longer weekly SAI $(n=39)$, with the difference that the skill gradient between Atlantic and Mediterranean catchments of the Iberian Peninsula becomes more obvious (see Table 1, fourth column).

\section{Discussion and conclusions}

The present study has shown that DJF precipitation totals on the Iberian Peninsula and southern Norway can be skillfully forecast from the previous October's snow advance index, which is available for operational seasonal prediction at the onset of November. Using linear regression in a 1-yr-out cross-validation framework, and applying the index based on daily satellite retrievals as only predictor variable, local precipitation totals in the former mentioned two regions have been hindcast with highly significant correlations of up to 0.84 and 0.71 , while the corresponding results for the spatially aggregated hindcast are 0.75 and 0.58 , respectively. These results outperform the skill of general circulation models (Doblas-Reyes et al. 2009; Frias et al. 2010) and competing empirical indices (Folland et al. 2012), and in case of the Iberian Peninsula, even exceed the predictability that can be potentially achieved by the latter (Folland et al. 2012).

With the recommendation to reassess these findings as the sample size of the daily snow advance index increases, we conclude that it is the most reliable source of predictability for wintertime precipitation on the Iberian Peninsula and southern Norway and underline the great potential of applying state-of-the art remote sensing products for the purpose of empirical forecasting in earth system science. Since the predictive power of Eurasian snow cover increase is highest in regions where general circulation models perform poorest, we support the hypothesis that optimizing the snow-atmosphere coupling in numerical models (Hardiman et al. 2008) is key for improving their skill.

Acknowledgments. SB, RM, and JMG acknowledge funding from the CICYT Project CGL2010-21869 and from QWeCI (EU Grant 243964) and the CSIC
JAE-PREDOC program. JC is supported by the National Science Foundation Grants ARC-0909459 and ARC-0909457, and NOAA Grant NA10OAR4310163. The authors are thankful for the helpful comments of the three anonymous reviewers and acknowledge the E-OBS dataset from the ENSEMBLES project (http:// ensembles-eu.metoffice.com/) as well the ECA\&D (http:// eca.knmi.nl/) and AEMET station datasets.

\section{REFERENCES}

Cohen, J., and M. Barlow, 2005: The NAO, the AO, and global warming: How closely related? J. Climate, 18, 4498-4513.

and J. Jones, 2011: A new index for more accurate winter predictions. Geophys. Res. Lett., 38, L21701, doi:10.1029/ 2011 GL049626.

_-, M. Barlow, P. J. Kushner, and K. Saito, 2007: Stratospheretroposphere coupling and links with Eurasian land surface variability. J. Climate, 20, 5335-5343.

Doblas-Reyes, F. J., and Coauthors, 2009: Addressing model uncertainty in seasonal and annual dynamical ensemble forecasts. Quart. J. Roy. Meteor. Soc., 135, 1538-1559, doi:10.1002/ qj. 464 .

Folland, C. K., A. A. Scaife, J. Lindesay, and D. B. Stephenson, 2012: How potentially predictable is northern European winter climate a season ahead? Int. J. Climatol., 32, 801-818.

Frias, M. D., S. Herrera, A. S. Cofino, and J. M. Gutierrez, 2010: Assessing the skill of precipitation and temperature seasonal forecasts in Spain: Windows of opportunity related to ENSO events. J. Climate, 23, 209-220.

García-Morales, M. B., and L. Dubus, 2007: Forecasting precipitation for hydroelectric power management: How to exploit GCM's seasonal ensemble forecasts. Int. J. Climatol., 27, 1691-1705, doi:10.1002/joc.1608.

Goddard, L., S. J. Mason, S. E. Zebiak, C. F. Ropelewski, R. Basher, and M. A. Cane, 2001: Current approaches to seasonal to interannual climate predictions. Int. J. Climatol., 21, 1111-1152, doi:10.1002/joc.636.

Hardiman, S. C., P. J. Kushner, and J. Cohen, 2008: Investigating the ability of general circulation models to capture the effects of Eurasian snow cover on winter climate. J. Geophys. Res., 113, D21123, doi:10.1029/2008JD010623.

Haylock, M. R., N. Hofstra, A. M. G. Klein Tank, E. J. Klok, P. D. Jones, and M. New, 2008: A European daily high-resolution gridded data set of surface temperature and precipitation for 1950-2006. J. Geophys. Res., 113, D20119, doi:10.1029/ 2008JD010201.

Hurrell, J., 1995: Decadal trends in the North Atlantic Oscillation: Regional temperatures and precipitation. Science, 269, 676679, doi:10.1126/science.269.5224.676.

Klein Tank, A. M. G., and Coauthors, 2002: Daily dataset of 20thcentury surface air temperature and precipitation series for the European Climate Assessment. Int. J. Climatol., 22, 14411453, doi:10.1002/joc.773.

Klok, E. J., and A. M. G. Klein Tank, 2009: Updated and extended European dataset of daily climate observations. Int. J. Climatol., 29, 1182-1191, doi:10.1002/joc.1779.

Kristjánsson, J., A. Staple, J. Kristiansen, and E. Kaas, 2002: A new look at possible connections between solar activity, clouds and climate. Geophys. Res. Lett., 29, 2107, doi:10.1029/2002GL015646. 
Livezey, R., and W. Chen, 1983: Statistical field significance and its determination by Monte Carlo techniques. Mon. Wea. Rev., 111, 46-59.

Michaelsen, J., 1987: Cross-validation in statistical climate forecast models. J. Climate Appl. Meteor., 26, 1589-1600.

Palmer, T. N., and Coauthors, 2004: Development of a European Multimodel Ensemble System for Seasonal-to-Interannual Prediction (DEMETER). Bull. Amer. Meteor. Soc., 85, 853-872.
Ramsay, B., 1998: The Interactive Multisensor Snow and Ice Mapping System. Hydrol. Processes, 12, 1537-1546.

Robinson, D., K. Dewey, and R. Heim Jr., 1993: Global snow cover monitoring: An update. Bull. Amer. Meteor. Soc., 74, 16891696.

Rodriguez-Puebla, C., A. Encinas, and J. Saenz, 2001: Winter precipitation over the Iberian Peninsula and its relationship to circulation indices. Hydrol. Earth Syst. Sci., 5, 233-244. 